\title{
Why Do Standardized ISO 14001 Environmental Management Systems Lead to Heterogeneous Environmental Outcomes? ${ }^{\text {Tे }}$
}

\author{
Haitao Yin $*$ and Peter J. Schmeidler ${ }^{2}$ \\ ${ }^{1}$ Antai College of Economics and Management, Shanghai JiaoTong University, Shanghai, China; \\ Erb Institute for Global Sustainable Enterprise, University of Michigan, Ann Arbor, MI, USA \\ ${ }^{2}$ Risk Management and Decision Processes Center, The Wharton School, University of Pennsylvania, \\ Philadelphia, PA, USA
}

\begin{abstract}
Institutional theories and resource-based views have suggested that, although they appear similar externally, standardized management systems may be implemented very differently in different organizations. This variability in implementation may be responsible for the heterogeneous performance of these standardized management systems. The current literature on the environmental impacts of ISO 14001 certification has largely neglected this phenomenon. Drawing on our survey of all US 14001 certificate holders, this study finds that great variability does exist in facilities' implementation of ISO 14001 standards. This heterogeneity has a significant impact on the linkage between ISO 14001 certification and facilities' environmental performance. In particular, we find that facilities that integrate ISO 14001 standards into their daily operations are more likely to report improvements in environmental performance. Environmental improvements are also more likely to occur in facilities that include performance management elements in their ISO 14001 standards. Furthermore, both types of facility are more likely to report that ISO certification contributes to this improvement. Neglecting the heterogeneity in facilities' implementation of ISO 14001 standards may explain the instability of findings from the empirical literature investigating the impacts of ISO 14001 certification. Theoretically, this paper informs the understanding of heterogeneous organizational behavior under isomorphic pressures. Copyright (C) 2008 John Wiley \& Sons, Ltd and ERP Environment.
\end{abstract}

Received 12 March 2008; revised 11 June 2008; accepted 12 June 2008

Keywords: environmental management; ISO 14001; heterogeneous organizational behavior; isomorphism; environmental performance

\footnotetext{
*Correspondence to: Haitao Yin, Antai College of Economics and Management, Shanghai JiaoTong University, 535 FaHua Zhen Rd, Shanghai, China 200052. E-mail: haitaoy77@hotmail.com

This paper is in memory of Peter J. Schmeidler who has devoted his career in the practice and research of corporate environmental management.

This article was published online on 8 December 2008. An error was subsequently identified and corrected by an erratum notice that was published online on [May 7 2009]. DOI: 10.1002/BSE [656]. This printed version incorporates the amendment identified by the erratum notice.
} 


\section{Introduction}

$\mathrm{O}$ $\mathrm{n}$ the heels of ISO 9000's success as a quality management standard, the International Organization for Standardization (ISO) established the ISO I400I Environmental Management System (EMS) Standard as a framework for facilities to manage their environmental issues. The promise of ISO I4OOI is that, by certifying to this standard, firms should have better control of their environmental operations, thereby mitigating their environmental footprints.

A body of literature has examined the question of whether ISO I400I certification is just 'greenwash' or can really lead to better environmental performance. The results from these studies have been notably uneven. After comparing facilities that have ISO-certified EMS with facilities that have uncertified EMS or no EMS at all, Potoski and Prakash (2005) and Kang (2005) found that the adoption of an ISO I400I certified EMS improved facilities' environmental performance. However, Dahlstrom et al. (2003) and Matthews (200I) reached the opposite conclusion. Some other studies narrow the control group to the facilities with uncertified EMSs, and look at whether the act of ISO certification (hereafter, we use the abbreviation ISO to stand for ISO I400I) can enhance environmental performance beyond an uncertified EMS. No agreement on this has been reached, either. Russo (2002) and Melnyk et al. (2003) found that firms that have gone through EMS certification experience a greater positive impact on environmental performance than firms that have not certified their EMS. However, King et al. (2005), Yin (2003), Jiang and Bansal (2003) and Andrews et al. (2003) found that ISO certification adds little value beyond establishing an EMS. For example, Jiang and Bansal (2003) concluded that 'ISO I4OOI certification provided little, if any, additional functional value to an in-house EMS except for external recognition, credibility and procedural legitimacy'.

In this literature that investigates the environmental impacts of ISO I4OOI certification, the ISO I4OOI certification is implicitly considered to be homogenous, precise and predictable. However, this treatment is not consistent with the wisdom that has been accumulated in the management literature on standardized management systems, notably ISO 9000 and ISO I400I. According to this literature, although identical management models may be adopted due to institutional pressures that lead organizations to become more isomorphic (DiMaggio and Powell, I983; Guler et al., 2002), great variability may exist in their implementation. According to institutional theory, this variability could be a result of facilities' internal norms, values and cultures (Oliver, I99I, I997; Scheid-Cook, I992). The resource-based view argues that internal capabilities and resources may be responsible for the variability (Barney, I986; Christmann, 2000). No matter what the underlying reason is, it seems to be a common phenomenon that standardized management tools could be implemented very differently. The current literature on the environmental impacts of ISO I4OOI certification has largely neglected the variability in how facilities implement the standards. This may explain the instability of the empirical findings from the literature.

The purposes of this paper are twofold. First, we look at the variability with which facilities implement ISO I400I standards. Second, and more importantly, we look at how this heterogeneity can explain different environmental impacts of ISO I400I certification. In this paper, we present an analysis of our survey of all US I4OOI certificate holders. We find a sizable variability in the extent to which facilities (I) integrate ISO I40oI standards with their daily operation and (2) include performance management elements in their ISO I4OOI standards. We also find that facilities that actively integrate ISO standards with their day-to-day operations are more likely to report a greater environmental performance improvement and that ISO certification contributes to the improvement to a greater extent than others. So are the facilities that include performance management elements in their ISO standards to a greater extent.

This study is of significance for several reasons. First, institutional theories and resource-based views argue that facilities may implement standardized management tools very differently even under isomorphic pressures. This study provides empirical evidence for this view in the context of ISO I4OOI certification, and further links the implementation variation with the performance of ISO I400I standards. Second, from a practical management point of view, this study can shed light on how ISO I400I certification can be improved to better serve the goal of promoting facilities' environmental performance, because a linkage between the implementation of ISO I4OOI certification and environmental performance is drawn. Finally, discovering how organizations' implementation of 
ISO I4OOI standards is associated with performance improvement may help resolve the ongoing controversy over the efficacy of ISO I400I certification. ${ }^{\mathrm{I}}$

The rest of the paper proceeds as follows. The following section demonstrates, based on a literature review, why standardized management systems could be implemented differently and how ISO I400I certification presents an opportunity for studying this. In the next section, we discuss methods, data and measures. The fourth section presents our empirical findings on the variability in which facilities implement ISO I4OOI certification and how this variability lead to different environmental impacts. The fifth section concludes with a discussion of major findings and future research.

\section{Theory and Hypotheses}

Because of their 'standardized' nature, management systems such as ISO 9000 and ISO I400I are often implicitly linked to an image of homogeneity and conformity. This image has been reinforced by a literature that studies their dissemination and adoption from an institutional theory perspective of isomorphism (Guler et al., 2002; Delmas, 2002). This view contends that organizational forms, culture and practices tend to become more isomorphic because of coercive, mimetic and normative pressures (DiMaggio and Powell, I983). These pressures arise largely from outside organizations. They tend to lead organizations to adopt similar practices and thereby become homogenous. It is probably because of this assumption of homogeneity that the variability of facilities' implementation of ISO I4OOI standards has not been explored in the literature investigating the environmental impacts of ISO I400I certification.

However, a body of literature has informed us that firms may implement identical management standards differently and do so strategically, even though their adoption is driven by external isomorphic pressures. Some institutional scholars are critical of the institutional literature for having placed too much emphasis on the homogeneity of organizations and lacked attention to the role of active agency and self-interest seeking behavior in organizations (Wooten and Hoffman, 2008; Delmas and Toffel, 2008). ${ }^{2}$ Oliver suggested that organizations craft strategic responses when confronted with institutional pressures (Oliver, I99I), and these strategic responses are a function of firms' internal culture, norms and values (Oliver, I997). As Hoffman (200I) noted, 'the form of organizational response is as much a reflection of the institutional pressures that emerge from outside the organization as it is the form of organizational structure and culture that exist inside the organization' (Hoffman, 200I, pp. I36-I37). Scheid-Cook (I992) studied the response of mental health organizations to a legal policy called outpatient commitment. She found that organizational responses were highly variable because each organization construed the workings of the policy according to its own definitions and stocks of knowledge. Delmas and Toffel (2008) demonstrated that internal organizational structure is key to explaining why organizations adopt heterogeneous management practices when facing similar external pressures.

While institutional theory emphasizes the role of organizational norms, values, cultures and structures in causing heterogeneity, the resource-based view provides an alternative explanation for variability by highlighting the role of facilities' internal capabilities and resources (Penrose, I959; Barney, I986). The resource-based view argues that the unique resources and capabilities that firms possess are important factors affecting the implementation and long-term performance of similar organizational practices. Teece (I986) introduced the concept of complementary assets. He suggested that, in order to materialize the benefit of new management practices, a firm needs to have assets that complement these practices. When studying incumbent firms' performance in face of new entrants, both Tripsas (I997) and Rothaermel (200I) highlighted that specialized complementary assets played a crucial role in determining the incumbents' performance. Drawing on this view, Christmann (2000) found that

\footnotetext{
${ }^{\mathrm{I}}$ It is especially important to have a better understanding of this controversy considering that special regulatory treatment has been proposed for firms adopting ISO I4OOI certification (Prakash, I999) and that some state governments have moved forward to do so (North Carolina Division of Pollution Prevention and Environmental Assistance, I998).

${ }^{2}$ The old institutionalism emphasizes the capacity of people and organizations to construct and enact their environment. In the shift from the old to the new institutionalism, the active role of organization is somewhat lost. The new institutionalism focuses on how organizational strategies and practices converge as a response to external isomorphic pressures. A research effort is now being made to wed the new and old perspectives (Wooten and Hoffman, 2008; Delmas and Toffel, 2008).
} 
capabilities for process innovation and implementation are complementary assets that moderate the relationship between best environmental management practices and cost advantage, a significant factor in determining firm performance.

These theories suggest that although they are adopted as a response to isomorphic pressures and appear similar externally, standardized management systems or strategies may be implemented very differently because of the variability in internal norms, cultures, resources and capabilities. Heterogeneous implementation normally leads to different outcomes. In fact, scholars have argued that varied implementation more likely occurs when the search for external legitimacy rather than internal efficiency drives adoption (Meyer and Rowan, I977; Boiral, 2003, 2007). Follett (I995) argued that if a standard is induced externally, independent thinking and customization play an important role in actual implementation. On the one hand, if they only have interest in external legitimacy that largely hinges on adoption rather than implementation, organizations may decide to adopt standards but fail to make real operational changes. On the other hand, if they value external legitimacy as well as internal efficiency, organizations may try hard to integrate the standards into their daily operations and even go beyond minimum standards.

That is to say, firms interpret and implement externally induced management tools based on their own internal norms, resources and needs, which results in great heterogeneity in implementation. In a study of ISO 9000, Boiral (2003) found that the implementation of ISO 9000 falls into three different groups: ceremonial integrators, quality enthusiasts and dissents. All these groups agree that external legitimacy greatly motivates the adoption of ISO 9000 standards. However, ceremonial integrators 'focused on superficially implementing the ISO requirements, while limiting the genuine changes to their work practices to a minimum' (Boiral, 2003, p. 726), quality enthusiasts were convinced of the intrinsic usefulness of ISO 9000 and faithfully implemented it and dissents believed that their organizations' decision to adopt ISO 9000 was a mistake and resisted implementation of the systems.

ISO I400I certification is another great case to illustrate this. Like ISO 900०, more often than not, ISO I400I certification is externally induced. In their study, Jiang and Bansal (2003) showed that facilities whose operations attract the attention of the public and facilities whose environmental impacts are hard to understand for external stakeholders are more likely to certify with ISO I400I standards. Andrews et al. (200I) also argued that facilities pursue ISO I400I certification as a public demonstration of environmental friendliness. Adams (I999), Delmas (2000) and Chapple et al. (200I) found that ISO I400I was adopted as a tool of gaining competitive advantage such as increasing international trade opportunities and forging a greater market share. Kang (2005) and Boiral (2007) highlighted the role of corporate head office in pressuring facilities to adopt ISO I400I standards.

In light of the theories advanced by institutional and resource-based scholars, although the adoption is a response to similar external pressures, facilities may implement ISO I4OOI standards very differently depending on their internal norms, resources and needs, and this heterogeneous implementation may lead to different performance of ISO I4OOI standards. Unfortunately, however, the heterogeneity of implementation, especially how it relates to the varied environmental impacts of ISO I4OOI certification, is largely absent from the current literature. The purpose of this paper is to highlight this heterogeneity and demonstrate how it could affect the environmental performance of ISO I400I standards.

Operationally, facilities can implement ISO I400I standards differently with respect to at least two aspects. First, facilities may integrate ISO I400I standards with their daily operations to different degrees. ISO I400I is a set of very flexible standards designed to apply to any organization regardless of size, type and location. Interviews by Dahlstrom et al. (2003) showed that ISO certification often was described as too flexible a standard to allow for specific guidance. When the management model is flexible enough to allow for considerable internal maneuvering, different levels of integration follow (Boiral, 200I, 2003, 2007). Some facilities may just proceed to do the bare minimum to gain certification. For these facilities, the adoption of the standardized management model never goes beyond paperwork. In contrast, other facilities may actively integrate ISO I400I certification into every aspect of their daily operations, involving their employees and production managers in the implementation of ISO I4OOI standards. In his study on ISO I400I, Boiral (2007) distinguished four strategies for integrating the ISO I400I system: ritual, decoupled, mobilized and proactive integration. In ritual and decoupled integration, organizations normally exercised a laissez-faire policy with respect to ISO I4OOI requirements, where practices were not questioned genuinely and very limited internal involvement occurred. In contrast, for mobilized and proactive 
integration, employees and production managers applied the ISO I400I standards, and environmental practices were changed.

The extent to which management tools are integrated with facilities' daily operations should affect the actual impacts of these management tools. On the one hand, while bare-minimum adoption may result in some improvement in a facility's environmental profile and can satisfy customers' demands, the level of improvement is limited without further action. On the other hand, facilities that actively integrate ISO I400I standards into their daily operations are more likely to obtain its full environmental benefits. As Jayathirtha (200I) contended, it 'will require buy-in from everyone, as well as the willingness to change current practices' to materialize the benefits of the ISO I4OOI standards. In their study of ISO 9000 standards, Naveh and Marcus (2004) found that the extent to which ISO 9000 is associated with performance improvement depends on the level of its integration. Therefore, we hypothesize the following.

Hypothesis 1. Facilities that integrate ISO 14001 standards into their daily operations to a greater extent will achieve a greater environmental performance improvement than those that do not.

Second, facilities may go beyond ISO I4OOI and use it as a springboard to introduce new environmental management tools. One thing facilities could do is to include performance management elements in their ISO I400I standards. ISO I400I certification is a process-based instrument with no performance requirements (Welch et al., 2002). As Delmas (2003) has emphasized, 'like ISO 9000, ISO I400I does not focus on outcomes, such as pollution [reduction], but focuses on process'. 'The standard does not require firms to provide information to the public on their environmental performance. Nor does it require improvement beyond regulatory compliance' (Delmas, 2003, pp. 4-5).

Because ISO I4OOI certification is process focused, it is totally at the facilities' discretion whether, and to what extent, to include performance management elements in its implementation. These performance management elements include activities to ensure that performance goals are clearly specified, that progress towards the goals is carefully measured and that goals are consistently being met. In their research on ISO 9000, Najmi and Kehoe (200I) found that the lack of an appropriate performance measurement system is a barrier to post-ISO 9000 quality development and organizational benefits. On the other hand, the desired performance is much more likely to be achieved in performance-based programs, because performance measure is clearly defined and improvement is carefully tracked.

An example of a performance-based voluntary environmental program is Performance Track, sponsored by the Environmental Protection Agency (EPA). In addition to establishing and maintaining a comprehensive EMS, a Performance Track member must have a framework for measuring specific environmental performance and commit to continuous improvement. Performance Track members must submit an online annual performance report (APR) to the EPA and the public. Inability to make any progress, or a decline in overall facility performance, may result in removal from the program (US EPA, 2005). The EPA Performance Track program has been viewed as a very successful program in terms of its members' performance improvements (US EPA, 2006). As such, scholars have suggested that some performance-based elements should be included in the ISO I400I certification system (Yin, 2003; Russo, 2003). In this paper, we investigate whether including performance management elements in ISO I4OOI standards to a greater extent can result in a greater environmental performance improvement. We hypothesize the following.

Hypothesis 2. Facilities that include performance management elements in their ISO 14001 standards to a greater extent will achieve a greater environmental performance improvement than those that do not.

\section{Methods and Data}

\section{The Survey of US ISO 14001 Certificate Holders}

A survey of all the US ISO I4OOI certified facilities ('survey' hereafter) was designed and undertaken by the Wharton Risk Management and Decision Processes Center in conjunction with the American National Standards 
Institute (ANSI)-American Society for Quality (ASQ) National Accreditation Board (ANAB) and Quality Systems Update (QSU) Publishing Company starting in July 2005 and ending in August 2006. To establish the validity of the survey questions, we shared the questionnaire with experts on ISO I400I certification, US registrars and researchers, and obtained comments from them. We then conducted a pilot survey, to which I4 respondents gave comments. The survey questionnaire was revised based on their feedback.

The survey was sent to 3I96 US ISO I400I certificate holders over the internet. One complication is that a single ISO I400I certification can be issued to a firm covering a number of its facilities or our contact might be replying for a number of his/her firm's certified facilities. Because of this, we developed two versions of the survey, one for single facilities and one for multiple facilities. We received a total of 335 single-facility responses and 86 multisite responses. We removed the responses that claimed to represent more than ten facilities to avoid skewing the analyses. We further omitted those responses that did not complete the pages on which environmental performance questions are asked. The final database upon which our analyses are performed includes 292 singlefacility responses and 64 multi-site responses. The 64 multi-site responses collectively represent a total of IIO certificates and 200 facilities.

\section{Estimation Techniques}

Multivariate regression analyses are performed to analyze the data. In order to address the self-selection bias in survey response, we compare the survey sample with the population of US ISO I400I certificate holders and propose appropriate methods accordingly.

The survey sample is first compared with the population of US certificate holders based on the distribution of the year of first obtaining ISO I400 I certification. Table I shows that, although the survey sample largely follows the trend of the number of certificates issued in the US over time, some of the years are overrepresented (e.g. 2005) and some of the years are underrepresented (e.g. 2000). We adopt two approaches to address the concern of the unbalanced representation of certificates issued in different years. First, we include 'years since certification' in the regression model to take into account the time effects. Second, we use post-stratification adjustment in a separate estimation (Regression Model 2) so that the samples are combined in the right proportions to get a more precise overall aggregate estimate. ${ }^{3}$ The industrial sector profiles of the US certificate holders and the survey

\begin{tabular}{|c|c|c|c|c|}
\hline \multirow[t]{2}{*}{ Year } & \multicolumn{2}{|c|}{ All ISO14001 certificate holders } & \multicolumn{2}{|c|}{ Surveyed ISO14001 certificate holders } \\
\hline & $\begin{array}{l}\text { Number of } \\
\text { certificates }\end{array}$ & $\begin{array}{c}\text { Percentage of } \\
\text { certificates }\end{array}$ & $\begin{array}{l}\text { Number of } \\
\text { certificates }\end{array}$ & $\begin{array}{c}\text { Percentage of } \\
\text { certificates }\end{array}$ \\
\hline 1996 & 24 & 0.48 & 4 & 1.06 \\
\hline 1997 & 59 & 1.18 & 9 & 2.39 \\
\hline 1999 & 209 & 4.17 & 27 & 7.16 \\
\hline 2000 & 465 & 9.27 & 18 & 4.77 \\
\hline 2001 & 603 & 12.02 & 36 & $9 \cdot 55$ \\
\hline 2002 & 893 & 17.81 & 53 & 14.06 \\
\hline 2003 & 1,225 & 24.43 & 77 & 20.42 \\
\hline 2004 & 949 & 18.92 & 80 & 21.22 \\
\hline
\end{tabular}

Table 1. Number of ISO 14001 certification in each year: survey sample versus all certificate holders Sources: Survey of US ISO 14001 certificate holders; Quality System Update (QSU) Publishing Company database of ISO 14001 certificate holders.

${ }^{3}$ In Regression Model 2, the analysis unit is certificate instead of facility. From the Quality System Update (QSU) Publishing Company database of ISO I4OOI certificate holders, we know how many certificates were issued in each year but not how many facilities were covered. Therefore, we can only post-stratify the sample based on certificate. 


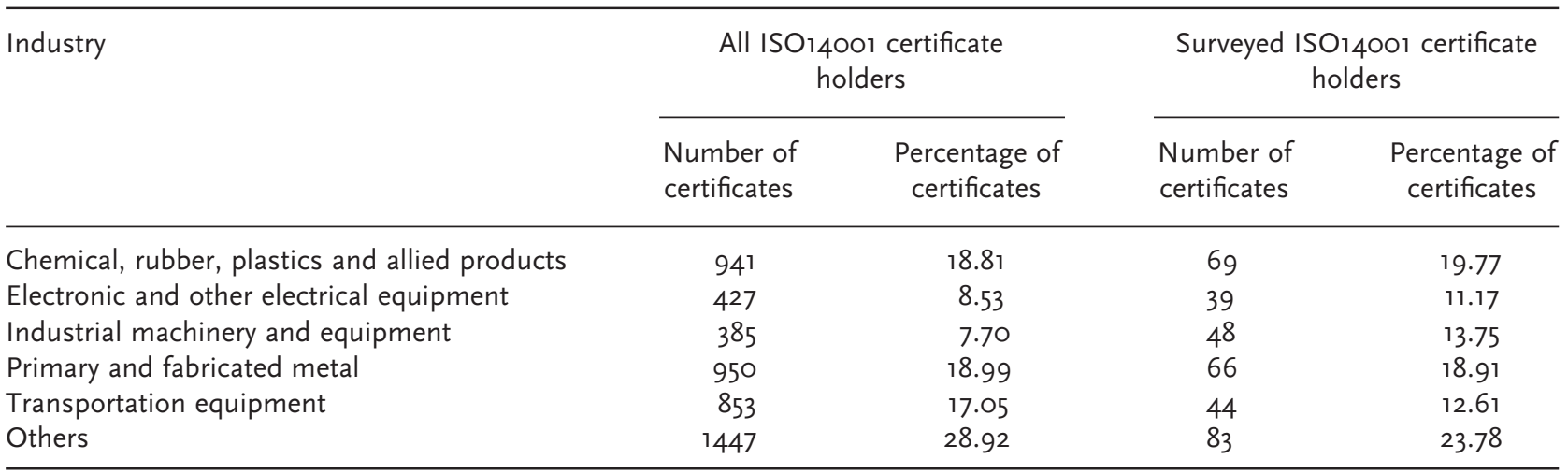

Table 2. Industrial sector profile of the survey sample and the population of US certificate holders Sources: Survey of US ISO 14001 certificate holders; Quality System Update (QSU) Publishing Company database of ISO 14001 certificate holders.

sample, as represented by their two digit Standard Industrial Classifications (SIC) codes, are presented in Table 2. It shows that the SIC code profile of the survey respondents is a good match to that of the US certificate holders except for the sectors of transportation equipment and industrial machinery and equipment. To control for the possibility that ISO I400I certification may have different impacts in different sectors, we include industry sector fixed effects in all our regression analyses.

A concern is that the analysis is likely to suffer from common method bias as the dependent variables and independent variables (detailed below) come from a common source (Podsakoff et al., 2003). We checked for the presence of common method bias by conducting an exploratory factor analysis with dependent variables and all the questions used to construct independent variables. If the dependent variable is heavily loaded on the factor underlying any one of the independent variables, there is evidence for common method bias (Delmas and Toffel, 2008; Burnett et al., 2005). Our analysis suggests that the dependent variables do not share a single factor with any of the independent variables. Therefore, we conclude that the common method bias does not raise a red flag and thus proceed to test our hypotheses with regular multivariate analyses.

\section{Dependent Variables}

In the survey, the respondents are asked to evaluate their facilities' environmental performance improvement after ISO I4OOI certification, and the extent to which the improvement can be attributed to the certification as it relates to ten environmental aspects, including permit violations, environmental fines, utility consumption, waste reduction, use of recycled material, environmental complaints, environmental incidents, land and habitat conservation, emergency preparedness and product environmental performance (for details, see the appendix).

Based on the respondent's self-evaluation, we constructed two indexes corresponding to the two survey questions noted above. The first one is called the Improvement Index, which is constructed as below:

$$
\text { Improvement_Index }_{j}=\sum_{i=1}^{\mathrm{IO}} \text { Improvement }_{i j} * \text { Aspect }_{i j} / \sum_{i=1}^{\mathrm{IO}} \text { Aspect }_{i j}
$$

where Aspect $_{i j}$ is an indicator variable, which is equal to unity if facility $j$ takes environmental aspect $i$ as one of its EMS goals and zero if it does not, and Improvement ${ }_{i j}$ is facility j's self-evaluation of the extent to which its performance on aspect $i$ has improved after certification on a I-5 scale. Not included in this analysis are those aspects that are not an EMS goal for a given facility, since not all of the io aspects are relevant to each facility.

Similarly, we constructed a Contribution Index. If a facility reported that its environmental performance improved after certification on one environmental aspect, we further ask them to evaluate the extent to which ISO certification has contributed to this improvement. Based on the answers to this question, we have two alternative ways to 
construct a Contribution Index to measure the extent to which ISO certification contributes to facilities' environmental performance improvement. We could leave the environmental aspects that do not demonstrate improvement after certification out of the analysis. Alternatively, the environmental aspects that do not demonstrate improvement after certification could be included and coded as no ISO certification contribution on this aspect. We tried both of these coding methods in the analysis. Because the conclusions do not depend on how we code the data, we report only the results based on the second coding method. The contribution index is constructed as below:

$$
\text { Contribution_Index }_{j}=\sum_{i=\mathrm{I}}^{\mathrm{IO}} \text { Contribution }_{i j} * \text { Aspect }_{i j} / \sum_{i=\mathrm{I}}^{\mathrm{IO}} \text { Aspect }_{i j}
$$

where Contribution ${ }_{i j}$ is facility j's self-evaluation of the extent to which ISO certification contributes to its environmental performance improvement on aspect $i$ on a $\mathrm{I}-5$ scale.

Note that the dependent variables in this study are based on the respondents' self-evaluation, not numerical data, such as annual tons of emissions. ${ }^{4}$ Although based on self-reported data, our measures have merit. Because our sample includes several widely differing industrial sectors, it is very hard, if not impossible, to find a numeric environmental performance metric that is relevant to all facilities and comparable between industries. Our measures focus on the environmental aspects facilities have identified as their EMS goals, and construct indexes based on these aspects. As such, the comparability across the facilities is warranted. Of course, we acknowledge the well known shortcomings of self-reported data and will suggest how we could use other data to complement this research in the concluding section.

\section{Independent Variables}

Two independent variables are constructed to test the research hypotheses proposed above, that is, whether the extent to which facilities (I) integrate ISO I4OOI standards into their daily operation and (2) include performance management elements in their ISO I4OOI standards is associated with the actual environmental impacts of ISO I400I standards.

\section{Integration}

Integration refers to the degree to which facilities have integrated the ISO I400I standards into various aspects of organizational life (Naveh and Marcus, 2004). We designed three questions to investigate three aspects of Integration, which are listed in the appendix. The Cronbach alpha reliability coefficient for these questions is 0.74 , which well exceeds the recommended minimum of 0.6 for combining them into one measure (Cortina, I993). We use the arithmetic mean of the answers to these three questions to measure the extent of integration.

\section{Performance Management Element}

In the survey, we designed three questions (see the appendix) to measure the extent to which facilities include performance management elements in their ISO I400I standards. The Cronbach alpha reliability coefficient for these questions is 0.89 , suggesting that they are measuring the same underlying construct. Again, we use the arithmetic mean of the answers to these three questions to measure the extent to which facilities have included performance management elements in their ISO I400I standards development and implementation.

\section{Control Variables}

The following variables are also included in the regression analyses as they potentially have an impact on the actual environmental impacts of ISO I400I certification.

\footnotetext{
${ }^{4}$ We had intended to use the EPA Toxic Release Inventory (TRI) data to construct the performance indicators. However, this effort has been impeded by the difficulties of identifying which respondents are in the TRI database. A survey question requesting TRI ID was unanswered by most of the respondents.
} 
Years After Certification

The period after certification is important because facilities may need some time to integrate the ISO I400I standards into their operation. That is to say, the effects of ISO I4OOI may not be evident until later years. Therefore, we postulated that the longer the time since certification, the greater the efficacy of ISO I4OOI standards is likely to be.

Number of Employees

We included the number of employees 5 at each facility to take into account the impact of facility size. One caveat of this variable is that $23 \%$ of the facilities did not report the number of employees in their response. Excluding these observations from the analyses causes a great loss of information. To address this missing data problem, we adopt two approaches. The first one is a dummy variable adjustment approach. More specifically, we created a dummy variable equal to unity if the data is missing and zero otherwise. For those with missing data, we substitute with the average number of employees at facilities that reported their number of employees. In the regressions, the natural log of the number of employees is used to account for the skewness of the data.

Alternatively, we use multiple imputation in Regression Model 3 to address the missing data problem. Multiple imputation replaces each missing value with one from an imputation process and then proceeds to the analysis as if there were no missing data. Both approaches have limitations (Allison, 200I), but their agreement in the estimation results suggests the robustness of our findings.

\section{Other Certifications}

The resource-based view (Teece, I986; Christmann, 2000) suggests that in order to materialize the benefit of new management practices a firm needs to have assets that complement these practices. These assets may include firms' experiences with other ISO standards. On the other hand, consistent with our integration argument, if the ISO I400I standards are not well integrated with other ISO standards already in place there may be a conflict between them that waters down the efficacy of ISO I400I certification. We include a dummy variable in the regression that is equal to unity if the facility is also certified to any of ISO900I, OHSASı800I, ISO/TSi6969 or QS9000 , and zero otherwise.

No EMS Before Certification

Facilities may have an in-house EMS long before ISO I400I certification, or they might develop a brand new EMS in the certification process. These two types of facility may have different experience with the environmental impacts of ISO I4OOI certification. To control this, we include the variable of 'no EMS before certification' in the regression analyses. If a facility had an EMS less than a year before the certification, we treat it as developing the EMS in the process of certification and code this variable as unity. On the other hand, for a facility that had developed its EMS more than a year before the ISO certification, we code it as zero.

Industry Fixed Effects

We classified all the facilities into six industrial sectors based on their reported two digit SIC code and description of certification scope: chemical, rubber, plastics and allied products (process industries); electronic and other electrical equipment; industrial machinery and equipment; primary and fabricated metal; transportation equipment and others. We include dummy variables for these industrial sectors to take into account the possibility that the efficacy of ISO certification may vary across different industrial sectors.

\footnotetext{
${ }^{5}$ Alternatively, we could use sales volume as the measure of facility size. We correlated the sales volume with the number of employees for those facilities that responded with answers to both questions and obtained a correlation coefficient of 0.74 . Since there are twice as many responses to the 'number of employees' question as to the 'sales volume' question and since the sales volume is highly correlated to the number of employees for our sample, we use the number of employees as the measure for facility size.
} 


\section{Empirical Findings}

Figures I and 2 show how facilities differ in the extent to which they (I) integrate ISO I400I standards into daily operation and (2) include performance management elements in their ISO I4OOI standards. It is clear that the implementation of ISO I4OOI standards is far from a homogenous and unambiguous phenomenon. Figure I summarizes facilities' assessment of the extent to which they have integrated ISO I4OOI standards into daily operation. About $40 \%$ of the facilities claimed that they integrated ISO I400I standards into their daily operation to a large or very large extent ( 4 or above), while about $32 \%$ of the facilities reported that they only carried out the

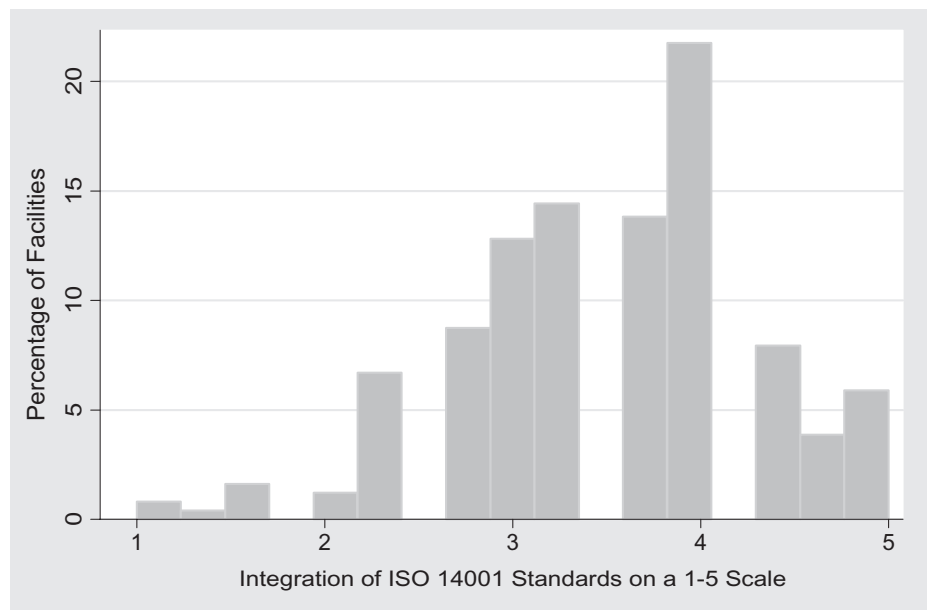

Note: The extent to which facilities integrated ISO 14001 standards into daily operation is assessed on a 1-5 scale, ranging from 1 (not at all) to 5 (very large extent). There are numbers with decimal points because we take the average of the answers to the three survey questions (on a 1-5 scale) when constructing the measure for integration (see the 'Methods and Data' section).

Figure 1. Facilities' assessment of the extent to which they integrated the ISO 14001 standards into daily operation

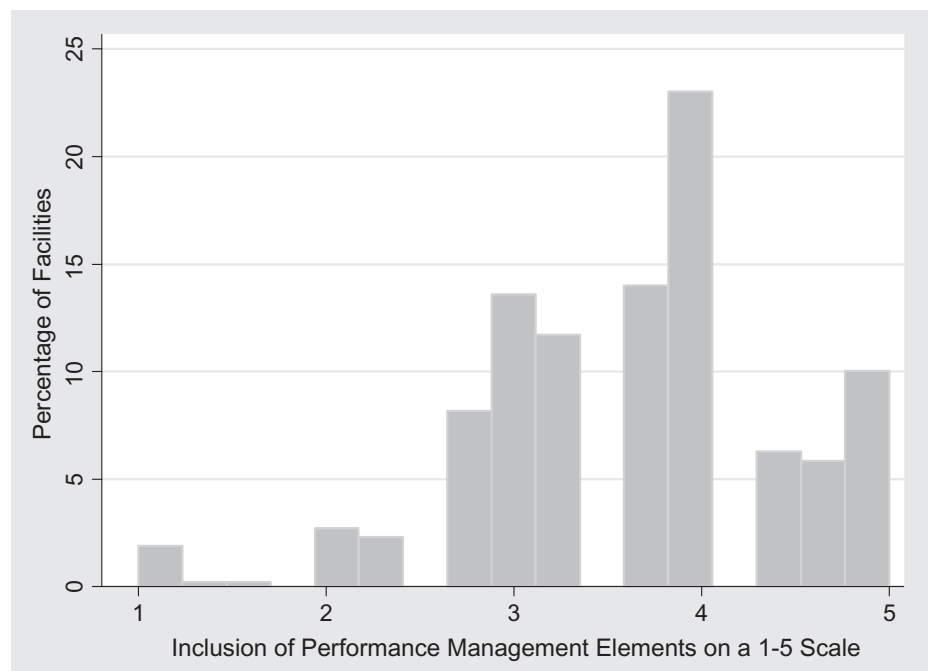

Note: The extent to which facilities included performance management elements in their ISO 14001 standards is assessed on a 1-5 scale, ranging from 1 (not at all) to 5 (very large extent). There are numbers with decimal points because we take the average of the answers to the three survey questions (on a 1-5 scale) when constructing the measure for the extent that performance management elements are included (see the 'Methods and Data' section).

Figure 2. Facilities' assessment of the extent to which they included performance management elements in their ISO 14001 standards 


\begin{tabular}{|c|c|c|c|c|c|c|c|c|c|c|c|}
\hline Variables & Mean & S.D. & (1) & $(2)$ & (3) & (4) & (5) & $(6)$ & (7) & $(8)$ & (9) \\
\hline Improvement index & 3.22 & 0.86 & 1.00 & & & & & & & & \\
\hline Years since certification & $3 \cdot 59$ & 2.31 & $0.12 *$ & 0.01 & 1.00 & & & & & & \\
\hline Employee missing & 0.24 & 0.43 & 0.03 & 0.06 & -0.04 & 1.00 & & & & & \\
\hline Natural log of employee & $5 \cdot 35$ & 1.31 & -0.03 & -0.05 & $0.29 *$ & & 1.00 & & & & \\
\hline No EMS before certification & 0.60 & 0.49 & 0.02 & $0.19 *$ & -0.03 & 0.05 & $-0.12 *$ & 0.04 & 1.00 & & \\
\hline Integration & 3.51 & 0.80 & $0.30 *$ & $0.25 *$ & 0.01 & 0.05 & -0.01 & 0.00 & $-0.10 *$ & 1.00 & \\
\hline Performance management element & 3.63 & 0.85 & $0.37 *$ & $0.49 *$ & 0.00 & 0.00 & -0.03 & 0.03 & $0.14^{*}$ & $0.39 *$ & 1.00 \\
\hline
\end{tabular}

Table 3. Means and correlations

$* p<0.05$.

integration to a medium or lesser extent. Notably, almost II\% percent of the facilities admitted that they made no or very few efforts for integration (a score no greater than $2.3^{6}$ ). Because the respondents are facility environmental managers, who tend to tout the virtues of ISO I400I standards due to a desire for legitimacy (Zbaracki, I998), this finding deserves attention. Similar findings (Figure 2) emerge for the extent to which facilities included performance management elements in their ISO I4OOI standards. About $45 \%$ of the facilities claimed that they include performance management elements in their ISO I400I standards to a large or very large extent (4 or above), while about $30 \%$ of the facilities reported that they did it to a medium or lesser extent, and more than $7 \%$ percent of the facilities admitted that they made no or very few efforts for performance management. These demonstrate that facilities vary significantly in how they design, develop and implement ISO I400I standards.

We now look at how implementation practices are associated with the environmental impacts of ISO I4OOI standards. The means and correlations of the variables are reported in Table 3 . The correlation coefficients between the dependent variables, Improvement Index and Contribution Index, and the two independent variables, Integration and Performance Management Element, are of particular interest. They suggest that facilities that had a higher level of integration and performance management are more likely to report a greater extent of environmental performance improvement after ISO I400I certification. These facilities are also more likely to report that the certification contributed to their environmental improvement to a greater extent than other respondents. This provides support for our research hypotheses. However, one may argue that these correlations may be due to some confounding factors that are correlated with both the dependent variables and the independent variables. For example, one may argue that the (positive) correlation between Improvement Index and Integration may not be because a higher level of Integration leads to greater improvement but due to Integration and performance improvement both being correlated with facilities' experience with other management standards. In order to alleviate this concern, we perform multivariate regression analyses that control some of the potential confounding factors.

For each of the dependent variables, environmental performance improvement after certification (Improvement Index) and the contribution of certification to the improvement (Contribution Index), three regression models are estimated. The first regression is our baseline model that regresses the two dependent variables on the independent variables of interest and the control variables with a weight that indicates the number of facilities each observation represents. Industry fixed effects are included. The second regression addresses the concern that our sample overrepresents some years while it under-represents others by including a post-stratification sampling weight that denotes the inverse of the probability that the observation is included. The third regression uses multiple imputation to address the missing data problem. In contrast, the first two regressions deal with this issue using a dummy variable adjustment approach. The estimations are reported in Tables 4 and 5 . The estimations are very consistent across the three regressions, especially for the variables of interest. This clearly demonstrates the robustness of our results.

\footnotetext{
${ }^{6}$ We have numbers with decimal points because we take the average of the three survey questions (on a I-5 scale) to construct the independent variables (see the previous section).
} 


\begin{tabular}{|c|c|c|c|}
\hline & $\begin{array}{c}(1) \\
\text { Improvement } \\
\text { index }\end{array}$ & $\begin{array}{c}(2) \\
\text { Improvement } \\
\text { index }\end{array}$ & $\begin{array}{l}\text { (3) } \\
\text { Improvement } \\
\text { index }\end{array}$ \\
\hline Years since certification & $\begin{array}{l}0.045^{*-k} \\
(0.017)\end{array}$ & $\begin{array}{l}0.058^{*} \\
(0.025)\end{array}$ & $\begin{array}{l}0.050^{*} \\
(0.020)\end{array}$ \\
\hline Employee missing & $\begin{array}{c}0.143 \\
(0.100)\end{array}$ & $\begin{array}{r}0.077 \\
(0.111)\end{array}$ & $\begin{array}{l}- \\
-\end{array}$ \\
\hline Natural log of employee & $\begin{array}{c}-0.030 \\
(0.034)\end{array}$ & $\begin{array}{l}-0.051 \\
(0.060)\end{array}$ & $\begin{array}{r}-0.060 \\
(0.036)\end{array}$ \\
\hline Other certification & $\begin{array}{c}-0.196 \% \\
(0.091)\end{array}$ & $\begin{array}{c}-0.102 \\
(0.122)\end{array}$ & $\begin{array}{c}-0.155 \\
(0.105)\end{array}$ \\
\hline No EMS before certification & $\begin{array}{c}0.032 \\
(0.078)\end{array}$ & $\begin{array}{c}0.071 \\
(0.101)\end{array}$ & $\begin{array}{c}-0.009 \\
(0.089)\end{array}$ \\
\hline Integration & $\begin{array}{l}0.198 * * \\
(0.050)\end{array}$ & $\begin{array}{l}0.153^{*} \\
(0.076)\end{array}$ & $\begin{array}{l}0.194^{* * *} \\
(0.058)\end{array}$ \\
\hline Performance management element & $\begin{array}{l}0.297^{\prime *} \cdot \\
(0.048)\end{array}$ & $\begin{array}{l}0.329 * x \\
(0.078)\end{array}$ & $\begin{array}{l}0.310 * * \\
(0.056)\end{array}$ \\
\hline Constant & 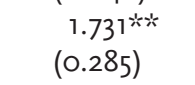 & $\begin{array}{l}1.588 \text { ' } \\
(0.485)\end{array}$ & $\begin{array}{l}1.820 \% * \\
0.316\end{array}$ \\
\hline Industry fixed effects & yes & yes & yes \\
\hline Observations (weight adjusted) & 456 & 321 & 492 \\
\hline$R$-squared & 0.18 & 0.21 & 0.20 \\
\hline
\end{tabular}

Table 4. Environmental performance improvement after ISO certification

Standard error in parentheses.

$* p<0.05 ; * * p<0.01$.

\begin{tabular}{|c|c|c|c|}
\hline & $\begin{array}{c}(1) \\
\text { Contribution } \\
\text { index }\end{array}$ & $\begin{array}{c}(2) \\
\text { Contribution } \\
\text { index }\end{array}$ & $\begin{array}{c}\text { (3) } \\
\text { Contribution } \\
\text { index }\end{array}$ \\
\hline Years since certification & $\begin{array}{c}0.010 \\
(0.018)\end{array}$ & $\begin{array}{c}0.001 \\
(0.027)\end{array}$ & $\begin{array}{c}0.012 \\
(0.024)\end{array}$ \\
\hline Employee missing & $\begin{array}{l}0.153 \\
(0.111)\end{array}$ & $\begin{array}{r}0.094 \\
(0.127)\end{array}$ & $\begin{array}{l}- \\
-\end{array}$ \\
\hline Natural log of employee & $\begin{array}{c}-0.002 \\
(0.038)\end{array}$ & $\begin{array}{c}-0.010 \\
(0.063)\end{array}$ & $\begin{array}{c}-0.024 \\
(0.045)\end{array}$ \\
\hline Other certification & $\begin{array}{c}-0.142 \\
(0.101)\end{array}$ & $\begin{array}{c}-0.156 \\
(0.135)\end{array}$ & $\begin{array}{l}-0.158 \\
(0.117)\end{array}$ \\
\hline No EMS before certification & $\begin{array}{l}0.335^{* * *} \\
(0.087)\end{array}$ & $\begin{array}{l}0.343^{* k} \\
(0.112)\end{array}$ & $\begin{array}{l}0.297^{* * *} \\
(0.100)\end{array}$ \\
\hline Integration & $\begin{array}{l}0.162 * * \\
(0.056)\end{array}$ & $\begin{array}{c}0.138^{+} \\
(0.079)\end{array}$ & $\begin{array}{l}0.134 * \\
(0.065)\end{array}$ \\
\hline Performance management element & $\begin{array}{l}0.503^{*} * \\
(0.053)\end{array}$ & $\begin{array}{l}0.521^{2} \times \\
(0.071)\end{array}$ & $\begin{array}{l}0.507 * * \\
(0.063)\end{array}$ \\
\hline Constant & $\begin{array}{c}0.560^{+} \\
(0.318)\end{array}$ & $\begin{array}{c}0.635 \\
(0.483)\end{array}$ & $\begin{array}{l}0.805^{*} \\
(0.362)\end{array}$ \\
\hline Industry fixed effects & yes & yes & yes \\
\hline Observations (weight adjusted) & 456 & 321 & 492 \\
\hline$R$-squared & 0.28 & 0.31 & 0.27 \\
\hline
\end{tabular}

Table 5. The contribution of ISO certification to the improvement Standard error in parentheses.

${ }^{+} p<0.10 ; * p<0.05 ; * * * 0.01$. 
The coefficients of Integration are positive and statistically significant in both Table 4 and Table 5. This suggests that facilities that integrated ISO I4OOI standards into their day-to-day operations to a larger extent are more likely to report a greater environmental performance improvement and more likely to attribute this improvement to ISO certification to a greater extent, compared with those who had a lower level of integration. This provides empirical support for Research Hypothesis I. More specifically, one unit increase in the level of Integration will raise the Improvement Index by 0.20 , and the Contribution Index by 0.16 . Considering a facility with an Improvement Index at the median level (5oth percentile), its Improvement Index would reach the 7oth percentile if its degree of Integration increased from 2 (low extent) to 4 (high extent).

Respondents' answers to one of our open-ended survey questions also highlight the importance of integration. The question asks 'What procedures/steps/efforts should your facility take in order to make ISO I400I more effective in improving environmental performance?'; one respondent, among many others, commented that, 'at this time the plant is using ISOI400I, QS9000, ISO900I, and MSM. Each standard is being implemented in isolation from the others. The next major step is to combine these systems into one. However, there is enough difference between the systems that the various managers involved are resistant to making the next big step'. Another answer to the same question was 'a better integration between production and EH\&S (Environment, Health and Safety). Sometimes ISO is perceived as the other system and not personalized'. All of these suggest that facilities need to make more efforts in integrating the ISO standards with their current operation in order to achieve a better environmental performance.

The estimated coefficient for the variable of Performance Management Element is positive and highly significant. This suggests that facilities that included performance management elements in their ISO I4OOI standards to a larger extent are more likely to report a greater environmental performance improvement and more likely to attribute this improvement to ISO certification to a greater extent compared with those who did it at a lower level. This provides empirical support for Research Hypothesis 2. More specifically, one unit increase in the level of including performance management elements will raise Improvement Index by 0.30 , and Contribution Index by 0.50. Considering a facility with a Contribution Index at the median level (50th percentile), its Contribution Index would reach almost 7oth percentile if its degree of including performance management elements increased from 2 (low extent) to 3 (medium extent).

In answering the open-ended questions, the respondents also suggest that adding performance management elements to ISO I400I design and implementation would be an effective way to improve the environmental impacts of ISO I4OOI certification. For example, when asked 'What procedures/steps/efforts should your facility take in order to make ISO I4OOI more effective in improving environmental performance?', one respondent commented that 'Responsible Care requires certain metrics and public disclosure. ISO-I4OoI is too easy to get with little real accountability'. Another stated, 'I think programs like EPA Performance Track [which include strong performance management elements] are good voluntary enhancements to ISO I400I certification that help to improve performance'.

Looking at the control variables, consistent with Russo (2007), facilities with longer history of ISO certification are more likely to report environmental performance improvement after certification. This suggests that the ISOcertified EMS takes time to reach its full strength. An ISO-certified EMS may not provide a quick resolution to environmental issues, but could be an effective tool for improving long-term environmental performance. The coefficient of 'other certification' is negative and is significant in two out of the three specifications in Table 4. This suggests that certification programs may conflict with each other if they are not carefully integrated, instead of complementing each other. This conflict may cause decreased effectiveness of certification programs. This finding provides additional support for the Integration argument highlighted above. The regressions (Table 5) also suggest that those who developed an EMS in the certification process are more likely to report that ISO certification contributes to their environmental performance improvement, compared with others. This may simply reflect the fact that those who developed EMS in the certification process experienced a larger organizational change during the certification process than those who developed EMS long before certification. 


\section{Discussions and Conclusions}

This study suggests that although organizations may adopt the same management tools in response to various institutional pressures and therefore become more isomorphic, this increasing isomorphism may be only an external phenomenon. Internally, the implementation of these management tools, such as ISO 9000 and ISO I4OOI, may be far from homogenous and unambiguous. In this paper, we find that some facilities actively integrate their ISO I400I-based EMS into their daily operation, while some facilities just follow the certification process as prescribed on paper with little customization. Some facilities include performance management elements in their ISO I400I-based EMS to a great extent while others do not. That is, facilities vary significantly in how they design, develop and implement their ISO I400I standards. This study provides empirical support for the arguments advanced by institutional theory and the resource-based view that facilities may implement standardized management tools very differently even under isomorphic pressures.

The studies done so far, especially the empirical literature on the environmental impacts of ISO I400I certification, have treated the certification as a homogenous phenomenon. That is, it is implicitly assumed that there is no difference in the design, development and use of ISO I400I standards among facilities. Our findings challenge this assumption. Different facilities have very different practices in developing and implementing ISO I400I standards. This heterogeneity furthermore has an impact on the linkage between ISO certification and facilities' environmental performance. Neglecting this heterogeneity may be the very reason for the instability of the findings on the environmental impacts of ISO I4OOI certification emerging from the current empirical literature. The study of the heterogeneity in facilities' ISO I4OOI practices and its impacts on facilities' environmental performance is missing from the literature. This research has been an effort to fill this gap.

The study provides evidence that facilities that have assimilated ISO I4OOI standards into their day-to-day operations to a larger extent are more likely to report a greater environmental performance improvement after certification and more likely to report that ISO certification contributed to the improvement to a greater extent, compared with those who had a lower level of integration. These findings suggest that the ISO certification should not only provide requirements regarding developing EMS, but more importantly stress that ISO I400I standards make their way into various aspects of organizational life - that is, they are actually implemented. For example, efforts should be made to ensure that facility employees and production managers are actively involved, and to ensure that ISO standards are better integrated with facilities' other management standards such as ISOgooo. This reinforces some revisions in the 2004 version of ISO I400I. For example, Section 4.2 (environmental policy) adds the need to communicate the environmental policy to all persons who work for or on behalf of the facilities, including their contractors.

Our study also presents evidence that facilities that included performance management elements in their ISO I4OOI standards to a larger extent are more likely to report a greater environmental performance improvement and more likely to report that ISO certification contributed to the improvement to a greater extent, compared with those who did it at a lower level. This suggests that performance management elements such as clearly defining performance goals, carefully measuring the progress towards the goals and ensuring the specified goals are met should also be included in the ISO certification process in order to better serve the purpose of promoting facilities' environmental performance. This confirms the appropriateness of some principles highlighted in the 2004 change of ISO certification, which states that all the environmental objectives and targets are useless unless they are implemented or achieved (Section 4.3.3 - environmental objectives and targets). This is also consistent with previous findings in the literature on voluntary environmental programs. King and Lenox (2000) argued that the failure of the early version of Responsible Care Program is at least partly due to the absence of clear performance goals and explicit sanctions for failing these goals. In contrast, Program 33/50, which is featured with clear performance goals and measures, has been widely praised as a successful example of voluntary environmental programs (Khanna and Damon, I999).

This study suggests some interesting future research. One limitation of this study is that we used self-reported data. This is partly due to the difficulties of obtaining a numeric environmental performance metric that is relevant to and comparable across different industrial sectors. Given the concern that nonresponses to the survey may be systematic, future research should use other approaches to further explore the propositions in this paper. One 
possibility is a sector-specific study for which a numeric environmental performance metric is available, for example, Toxic Release Inventory (TRI) data for the chemical and other process industries. Second, future research should further differentiate facilities based on their design and implementation of ISO I4OOI standards, and other voluntary environmental programs in general. One important message from this study is that heterogeneous implementation has to be acknowledged in future investigation of the effectiveness of voluntary environmental programs. This is important for achieving a better design to maximize the efficacy of voluntary environmental programs. For example, in order to design measures to ensure integration, studies need to be done to find out why facilities demonstrate different levels of integration, and to understand performance change at facilities with different levels of integration. This could be done through in-depth case studies on individual facilities that have exhibited high and low levels of integration in our survey.

\section{Acknowledgements}

We wish to thank Gabe Silvasi, of the OPIM Department at the Wharton School, who created the website that hosted the survey. Thanks to Paul Scicchitano and his staff at QSU Publishing Company for administering the delivery of the survey via the internet and the follow-up to nonresponders. We appreciate the help and comments we received from Bob King, CEO of ANAB, and that of ANAB's Environmental Council. Our colleagues at the Wharton Risk Management and Decision Processes Center and the Erb Institute for Global Sustainable Enterprise, Irv Rosenthal, Ulku Oktem, Tom Lyon and Howard Kunreuther, helped us to develop the survey instrument and provided comments for this paper. Financial support from the Erb Institute for Global Sustainable Enterprise and the Wharton Risk Management and Decision Processes Center is gratefully acknowledged.

\section{Appendix: Key Survey Questions Used in Analysis}

\section{Dependent Variables}

In this section, we are interested in getting to know the potential environmental and financial benefits from ISO I400I certification/RC I400I registration.

\begin{tabular}{|l|l|l|}
\hline Aspects & $\begin{array}{l}\text { Since gaining ISO 14001 certification/RC } \\
\text { 14001 registration to what extent has your } \\
\text { facility improved the performance on the } \\
\text { following aspects? }\end{array}$ & $\begin{array}{l}\text { To what extent is ISO 14001 certification/RC } \\
\text { 14001 registration responsible for the change? } \\
\text { If you mark 'not at all' in the first question, } \\
\text { do not mark anything in this question. }\end{array}$ \\
\hline Fewer permit violations & $\begin{array}{l}\text { 1. not at all 2. low extent 3. medium extent } \\
\text { 4. high extent 5. very high extent }\end{array}$ & $\begin{array}{l}\text { 1. not at all 2. low extent 3. medium extent } \\
\text { 4. high extent 5. very high extent }\end{array}$ \\
\hline $\begin{array}{c}\text { Fewer environmental fines } \\
\text { 1. not at all 2. low extent 3. medium extent } \\
\text { 4. high extent 5. very high extent }\end{array}$ & $\begin{array}{l}\text { 1. not at all 2. low extent 3. medium extent } \\
\text { 4. high extent 5. very high extent }\end{array}$ \\
\hline $\begin{array}{c}\text { Lower utility consumption } \\
\text { (fuel, water, electricity) }\end{array}$ & $\begin{array}{l}\text { 1. not at all 2. low extent 3. medium extent } \\
\text { 4. high extent 5. very high extent }\end{array}$ & $\begin{array}{l}\text { 1. not at all 2. low extent 3. medium extent } \\
\text { 4. high extent 5. very high extent }\end{array}$ \\
\hline $\begin{array}{c}\text { Greater waste reduction } \\
\text { 1. not at all 2. low extent 3. medium extent } \\
\text { 4. high extent 5. very high extent }\end{array}$ & $\begin{array}{l}\text { 1. not at all 2. low extent 3. medium extent } \\
\text { 4. high extent 5. very high extent }\end{array}$ \\
\hline $\begin{array}{c}\text { Greater use of recycled } \\
\text { material }\end{array}$ & $\begin{array}{l}\text { 1. not at all 2. low extent 3. medium extent } \\
\text { 4. high extent 5. very high extent }\end{array}$ & $\begin{array}{l}\text { 1. not at all 2. low extent 3. medium extent } \\
\text { 4. high extent 5. very high extent }\end{array}$ \\
\hline $\begin{array}{c}\text { Fewer environmental } \\
\text { complaints (odors, } \\
\text { noise, vibration etc.) }\end{array}$ & $\begin{array}{l}\text { 1. not at all 2. low extent 3. medium extent } \\
\text { 4. high extent 5. very high extent }\end{array}$ & $\begin{array}{l}\text { 1. not at all 2. low extent 3. medium extent } \\
\text { 4. high extent 5. very high extent }\end{array}$ \\
\hline $\begin{array}{l}\text { Fewer environmental } \\
\text { incidents (discharges, } \\
\text { emission, spills, } \\
\text { accidents etc.) }\end{array}$ & $\begin{array}{l}\text { 1. not at all 2. low extent 3. medium extent } \\
\text { 4. high extent 5. very high extent }\end{array}$ & $\begin{array}{l}\text { 1. not at all 2. low extent 3. medium extent } \\
\text { 4. high extent 5. very high extent }\end{array}$ \\
\hline
\end{tabular}




\begin{tabular}{|l|l|l|}
\hline $\begin{array}{c}\text { Greater land and habitat } \\
\text { conservation }\end{array}$ & $\begin{array}{c}\text { 1. not at all 2. low extent 3. medium extent } \\
\text { 4. high extent 5. very high extent }\end{array}$ & $\begin{array}{c}\text { 1. not at all 2. low extent 3. medium extent } \\
\text { 4. high extent 5. very high extent }\end{array}$ \\
\hline $\begin{array}{l}\text { Improved emergency } \\
\text { preparedness }\end{array}$ & $\begin{array}{c}\text { 1. not at all 2. low extent 3. medium extent } \\
\text { 4. high extent 5. very high extent }\end{array}$ & $\begin{array}{c}\text { 1. not at all 2. low extent 3. medium extent } \\
\text { 4. high extent 5. very high extent }\end{array}$ \\
\hline $\begin{array}{l}\text { Better product } \\
\text { environmental } \\
\text { performance }\end{array}$ & $\begin{array}{l}\text { 1. not at all 2. low extent 3. medium extent } \\
\text { 4. high extent 5. very high extent }\end{array}$ & $\begin{array}{c}\text { 1. not at all 2. low extent 3. medium extent } \\
\text { 4. high extent 5. very high extent }\end{array}$ \\
\hline
\end{tabular}

Please indicate whether the following environmental aspects are among your EMS's major environmental performance goals? [Check all that apply]

Fewer permit violations

Fewer environmental fines

Lower utility consumption (fuel, water, electricity)

Greater waste reduction

Greater use of recycled material

Fewer environmental complaints (odors, noise, vibration etc.)

Fewer environmental incidents (discharges, emission, spills, accidents etc.)

Greater land and habitat conservation

Improved emergency preparedness

Better product environmental performance

None of the above

No response

\section{Independent Variables}

Integration

- To what extent did the design and development of your ISO I400I-based EMS involve participation by the managers at your facility?

- To what extent was the design and development of the ISO I400I-based EMS based on involvement by the employees?

- Has the use of the ISO I400I-based EMS become part of your regular routines?

\section{Inclusion of Performance Management Elements}

- To what extent has the organization improved the specificity and measurability of its environmental objectives and targets through ISO I4OoI certification?

- To what extent has the organization improved its use of performance indicators to measure progress in achieving its environmental objectives and targets through ISO I400I certification?

- To what extent has the organization improved its commitment to achieve its environmental objectives and targets through ISO I400I certification?

\section{References}

Adams R. I999. ISO I400I: a key ingredient of competitive edge. Environmental Law Management II(3): I03-IO4.

Allison P. 200I. Missing Data. Sage: Thousand Oaks, CA.

Andrews RN, Amaral D, Darnall N, Gallagher DR, Edwards D Jr, Huston A, Amore CD, Sun L, Zhang Y. 2003. Environmental Management Systems: Do They Improve Performance? http://ndems.cas.unc.edu/ [25 February 2007].

Andrews RN, Charm J, Habicht H, Knowlton T, Sale M, Tschinkel V. 200I. Third-Party Auditing of Environmental Management Systems: U.S. Registration Practices for ISO 14001. http://www.ndol.org/documents/emsreport.pdf [25 February 2007].

Barney JB. I986. Strategic factor markets: expectations, luck and business strategy. Management Science 32: I23I-I24I.

Boiral O. 200I. ISO I400I certification in multinational firms: the paradoxes of integration. Global Focus I3(I): 79-94.

Boiral O. 2003. ISO 9000, outside the iron cage. Organization Science I4(6): 720-737. 
Boiral O. 2007. Corporate greening through ISO I400I: a rational myth? Organization Science I8(I): I27-I46.

Burnett MF, Williamson IO, Bartol KM. 2005. Personality as a determinant of employees' reactions to justice and organizational reward perspectives: a cognitive affective perspective. Academy of Management Best Paper Proceedings.

Chapple W, Cooke A, Galt V, Paton D. 200I. The characteristics and attributes of UK firms obtaining accreditation to ISO I400I. Business Strategy and the Environment Io: 238-244.

Christmann P. 2000. Effects of 'best practices' of environmental management on cost advantage: the role of complementary assets. The Academy of Management Journal 43(4): 663-680.

Cortina JM. I993. What is coefficient alpha? An examination of theory and applications. Journal of Applied Psychology 78(I): 98-104.

Dahlstrom K, Howes C, Leinster O, Skea J. 2003. Environmental management systems and company performance. European Environment I3: I $87-203$.

Delmas M. 2000. Barriers and incentives to the adoption of ISO I400I in the United States. Duke Environmental Law and Policy Forum Fall: $\mathrm{I}-38$.

Delmas M. 2002. The diffusion of environmental management standards in Europe and in the United States: an institutional perspective. Policy Sciences 35: 9I-II9.

Delmas M. 2003. In Search of ISO: an Institutional Perspective on the Adoption of International Management Standards, Stanford Graduate School of Business Research Paper I784.

Delmas M, Toffel MW. 2008. Organizational responses to environmental demands: opening the black box. Strategic Management Journal 29(I0): I027-I055.

DiMaggio P, Powell WW. I983. The iron cage revisited: institutional isomorphism and collective rationality in organizational fields. American Sociological Review 48(2): 147-160.

Follett MP. I995. Prophet of Management: a Celebration of Writings from the 1920's. Harvard Business School Press: Boston, MA.

Guler I, Guillén MF, Macpherson JM. 2002. Global competition, institutions, and the diffusion of organizational practices: the international spread of ISO 9000 quality certificates. Administrative Science Quarterly 47(2): 207-232.

Hoffman AJ. 200I. Linking organizational and field-level analyses: the diffusion of corporate environmental practice. Organization and Environment I4(2): $133-156$.

Jayathirtha RV. 200I. Combating environmental repercussions through 'TQEM' and 'ISO I400o'. Business Strategy and the Environment Io: $245-250$.

Jiang RJ, Bansal P. 2003. Seeing the need for ISO I400I. Journal of Management Studies 40(4): 1047-I067.

Kang Y. 2005. Third Party Inspections on Environmental and Safety Regulation: Theory and Empirical Evidence, Ph.D. Dissertation. University of Pennsylvania: Philadelphia, PA.

Khanna M, Damon LA. I999. EPA's voluntary 33/50 Program: impact on toxic releases and economic performance of firms. Journal of Environmental Economics and Management 37(I): I-25.

King AA, Lenox MJ. 2000. Industry self-regulation without sanctions: the chemical industry's Responsible Care Program. Academy of Management Journal 43(4): 698-716.

King AA, Lenox MJ, Terlaak A. 2005. The strategic use of decentralized institutions: exploring certification with the ISO I400I management standard. Academy of Management Journal 48(6): io9I-IIo6.

Matthews DH. 200I. Assessment and Design of Industrial Environmental Management Systems, Ph.D. Dissertation. Carnegie-Mellon University: Pittsburgh, PA.

Melnyk SA, Sroufe RP, Calantone R. 2003. Assessing the impact of environmental management systems on corporate and environmental performance. Journal of Operations Management 2I: 329-35I.

Meyer J, Rowan B. I977. Institutionalized organizations: formal structure as myth and ceremony. The American Journal of Sociology 83(2): $340-363$.

Najmi M, Kehoe DF. 200I. The role of performance measurement systems in promoting quality development beyond ISO 9000 . International Journal of Operations and Production Management 2I(I/2): I59-I72.

Naveh E, Marcus AA. 2004. When does the ISO 9000 quality assurance standard lead to performance improvement? Assimilation and going beyond. IEEE Transactions on Engineering Management 5I(3): $352-363$.

North Carolina Division of Pollution Prevention and Environmental Assistance. I998. Summary of ISO 14001 State Activity. http://www.p2pays. org/ref\%5Coi/00324.pdf [27 February 2007].

Oliver C. I99I. Strategic responses to institutional processes. The Academy of Management Review I6(I): I45-I79.

Oliver C. I997. Sustainable competitive advantage: combining institutional and resource based views. Strategic Management Journal I8(9): 697-713.

Penrose ET. 1959. The Theory of the Growth of the Firm. Blackwell: Oxford.

Podsakoff PM, MacKenzie SB, Lee J-Y, Podsakoff NP. 2003. Common method biases in behavioral research: a critical review of the literature and recommended remedies. Journal of Applied Psychology 88(5): 879-903.

Potoski M, Prakash A. 2005. Covenants with weak swords: ISO I4O0I and facilities' environmental performance. Journal of Policy Analysis and Management 24(4): 745-769.

Prakash A. I999. A new-institutionalist perspective on ISO I4000 and Responsible Care. Business Strategy and the Environment 8: 322-335.

Rothaermel FT. 200I. Incumbent's advantage through exploiting complementary assets via interfirm cooperation. Strategic Management Journal 22: $687-699$.

Russo MV. 2002. Institutional change and organizational strategy: ISO I400I and emissions in the electronics industry. Academy of Management Best Papers Proceedings. 
Russo M. 2003. Adding Symbols to Substance: Theories of Organizational Strategy, ISO 14001, and Toxic Emission, working paper.

Russo M. 2007. Explaining the impact of ISO I400I on emission performance: a dynamic capabilities perspective on process and learning. Business Strategy and the Environment. DOI: 10.1002/bse.587

Scheid-Cook T. I992. Organizational enactments and conformity to environmental prescriptions. Human Relations 45(6): 537-554.

Teece D. I986. Profiting from technological innovation: implications for integration, collaboration, licensing, and public policy. Research Policy I5: $295-305$.

Tripsas M. I997. Unraveling the process of creative destruction: complementary assets and incumbent survival in the typesetter industry. Strategic Management Journal I8: II9-I42.

US Environmental Protection Agency (EPA). 2005. Performance Track Program Guide. http://www.epa.gov/performancetrack/downloads/ PTprog_guide.pdf [25 February 2007].

US Environmental Protection Agency (EPA). 2006. Leading Change: Performance Track 4th Annual Progress Report. http://www.epa.gov/ performancetrack/downloads/PT_4th_Progress_Report.pdf [25 February 2007].

Welch EW, Mori Y, Aoyagi-Usui M. 2002. Voluntary adoption of ISO I4000 in Japan: mechanisms, stages and effects. Business Strategy and the Environment II: 43-62.

Wooten M, Hoffman A. 2008. Organizational fields: past, present and future. In Handbook of Organizational Institutionalism, Greenwood R, Oliver C, Suddaby R, Sahlin-Andersson K (eds). Sage Publications Ltd: London.

Yin H. 2003. ISO 14001 Certification: Engine or Signal for Good Environmental Performance?, working paper.

Zbaracki MJ. I998. The rhetoric and reality of total quality management. Administrative Science Quarterly 43(3): 602-636. 